\title{
REMIXING OPINIONS: VIDEO QUOTATIONS AND STANCES IN VIDEO PRESS REVIEWS
}

\author{
Marjut Johansson $^{1}$
}

This paper aims to analyse video press reviews, which are digital press videos that are composed of several video quotations. Although the quotations originate from different media sources, they are linked intertextually because they contain opinions about the same political events. The quotations contain an evaluative stance about political events. The video quotations are edited into a new media story. Although the video press review is based on the selection of journalistic content and interpretation of media material, it has novel characteristics that make it a transformed and hybrid genre. In the cases analysed, there is no explicit journalistic voice to comment on the quoted material or the quoted persons. The origin of the quotations is not identified in every case. In this sense, the video press review does not fulfil the exigencies of reliability of information. The journalistic stance consists of composing a new story that relies on the viewers' capacity to recognise the genre's similarity to social media videos and independently draw conclusions about the meaning of the news information after reviewing quoted material.

Videos are an integral part of digital news information and online journalism in contemporary online newspapers and news sites. Videos range from entertaining, funny viral videos to traditional hard news videos that resemble broadcast news. The former can constitute a major part of the video offerings in online tabloid newspapers. The latter can either be news stories or may simply be sound bites excerpted

1 Marjut Johansson est Professeur à l'Université de Turku.

Recherches en communication, $\mathrm{n}^{\circ} 40$ (2013). 
from larger units of previously displayed material, such as a televised speech (Johansson 2012). News videos may be presented in a separate video section or inserted within a news article. This paper contributes to 'neojournalism' by examining how one traditional news genre, the press review, changes into a new type of journalistic practise.

Several French online newspapers and news sites have introduced télézapping videos. Télézapping refers to changing between or surfing TV channels, and it was first introduced in the TV's channel Canal+ in the 1990s ${ }^{1}$. Today, for instance, DailyMotion, iTélé, La Libération, and Rue89, among other websites, publish this type of videos. The multimedia section of Lemonde.fr includes a section called Télézapping:

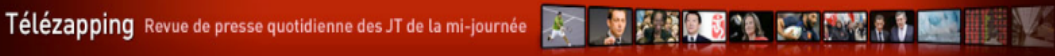

Image 1. Télézapping section of Le Monde, July 16, 2012

Here, the banner describes the section as a daily press review of midday television news. The genre characterisation that the newspaper assigns to these videos is adopted.

The press review is an opinion-related genre. In a printed newspaper, the reviews contain quotations from other newspapers. Quotations are an integral part of any news genre because they convey events, facts, opinions and views expressed by different individuals. They are recontextualised from various sources, other news stories and news commentaries that establish intertextual and interdiscursive links between texts and discourses in society. At the linguistic level, quotations are utterances that include stances in regard to various objects in the world. Social actors evaluate themselves, position themselves and (dis) align themselves with other actors (DuBois 2007:163). This paper aims to study what types of quotations are expressed in a video press review. This paper will ask the following research questions: 1) whose opinions are quoted in video press reviews, and what are their stances? 2) how are the quotations organised interactionally and/or discursively? and 3) how are the journalistic stances constructed?

The theoretical framework draws upon several research traditions. It is based on a view of language use as situated and anchored in interactional sociolinguistics and dialogical linguistics as well as in approaches to media and digital discourses. In addition, studies of

1 I thank Arnaud Mercier for this observation. 
online journalism and the role of readers and users in the digital culture will be considered.

\section{Digital news videos}

\section{Digital culture and liquid journalism}

What does the term digital mean? The term digital may describe a vast array of technological developments (Gere 2002:11), however it is often used interchangeably with other terms such as electronic, virtual, online, and computer-mediated:

To speak of the digital is to call up, metonymically, the whole panoply of virtual simulacra, instantaneous communication, ubiquitous media, and global connectivity that constitutes much of our contemporary experience. It is to allude to a vast range of applications and media forms that digital technology has made possible, including virtual reality, digital special effects, digital film, digital television, electronic music, computer games, multimedia, the Internet, the World Wide Web (...) (Gere 2002:11)

Digital culture, however, extends beyond technological development. According to Gere (2002:12-13), it denotes a "particular way of life of a group or groups of people at a certain period in history", encompassing artefacts and communication, including ways of thinking and using technology (Gere 2002:13). Contemporary societies and cultures are in constant flux, full of uncertainties, and driven by individual needs, problems, and struggles - Bauman $(2005,2011)$ calls this a liquid modern world that makes us constantly change our identities. These transformations occur in socio-cultural practises and in the discourses describing them.

In journalism, numerous new practises have been adopted, such as network journalism, citizen journalism, video-journalism, and neo-journalism, among others. According to Deuze (2008), journalism has also become liquid because it is driven by the interests of individual readers. The online context of news allows user participation in collecting the news according to the user's own interests and needs (Deuze 2006). The major act of "reading the news" has become one 
of monitoring, that is, the individualised gathering of information according to personal needs (Deuze 2008).

In the framework of digital culture, a certain perspective has to be adopted in regard to the nature of media products:

A study of content has always rested on the premise that it actually exists, that it genuinely can be considered as a finished, static object of study. In current media ecology of endless remixes, mash ups, and continuous edits, that is a problematic assumption. (...) in a digital culture, the roles, identities and activities of the people implicated in these categories are constantly shifting and, if anything, are less than clear-cut (...) (Deuze 2008:861, emphasis added)

Based on this view, digital press videos are considered dynamic objects of study. They are edited media products whose video quotations can be interpreted.

\section{Videos in digital news discourse}

Videos are recent additions to digital newspapers. Layton (2008) dates their existence to the beginning of the millennium but suggests that their use exploded six or seven years after their initial appearance. They are an integral part of any digital newspaper today. According to a recent documentary, The New York Times publishes more than 100 videos per month (Rossi 2011). All major online newspapers have sections devoted to videos that can be consequently divided into the same type of sections as news stories. In digital newspapers, videos range from funny news stories to many other types of news. According to Johansson (2012), the different types of political news videos published in online newspapers can be distinguished along several axes. First, as media products, they can be public videos produced institutionally either by the newspaper itself or by other news agencies. For example, although Helsingin Sanomat, a major Finnish newspaper, produces its own videos on domestic affairs, it also publishes videos produced by Reuters on international affairs. These videos represent a familiar way of conveying news because they resemble broadcast TV news reports. However, from a journalistic perspective, there can be differences. TV broadcast news is based on group work, whereas newspaper videos are often produced by a single video-journalist (Wallace 2009; Bock 2011). 
Second, videos can contain independent news stories, or they can include excerpts (Johansson 2012). They can resemble traditional news stories with the voiceover of the journalist, or they can show interviews with a journalist and a politician. If they use excerpts, they have usually been broadcast previously in other media. For instance, excerpts can be sound bites from public announcements, speeches or interviews. When videos are filmed by readers or if their origins remain unclear, they contain footage of events without any specific storyline or editing. For example, in some cases a hidden camera is intended to prove the factuality of a state of affairs described in the written article.

Third, the relationship of the videos and the news articles they are published within also varies (Johansson 2012). Videos may function as a parallel news story, containing a similar story to the written news article. They can also be used as quotations for the written story. In these cases, the videos are integrated into the news article, and the videos and texts form a multimodal type of news entity. Finally, the videos are used as evidence to support a claim made in a written news article. In a digital news interaction, videos may create an opportunity for users to participate in the reception and interpretation of the news.

\section{Press review as communicative genre: quotations and stances}

\section{Press review}

Communicative genres are forms of socio-cultural encounters between social actors. They belong to situated contexts, and they may change due to changes in society. In news media encounters, there are at least two frames of interaction: the one between the journalists and the events or the people whose story needs to be told and the one between the media instance and its publics (Lauerbach \& Fetzer 2007). Newspapers can participate in opinion formation through certain genres, such as editorials, op-ed pages, columns, and journalists' blogs. Although a press review does not express a newspaper's opinion, it is an opinionrelated genre (Erbe 2007:79)

because:

(...) media explicitly quote each other's opinions or main preoccupations. This practise is an intentional linking of different public arenas; a miniature public sphere is created 
within the same page of a newspaper or within ten minutes of a radio programme (Erbe 2007:79).

Although a press review is a traditional journalistic genre used in newspapers, TV, and radio, there is no single, fixed type. Erbe (2007:80) distinguishes three types - a press review of individual voices with quotations, a commented joint review based on summarising, and an index review that provides links to news stories that can be found elsewhere. Even when press reviews do not contain an explicit journalistic voice, the reviews are based on journalistic work.

Press reviews are, and have been, metadiscourses about events in the society, based on a selection of quotations (Erbe 2007; Claquin 1993). In her analysis of a radio press review, Claquin (1993) found that most of the quotations were taken from the print media, such as editorials or articles based on experts' views. In presenting the quoted views, journalists distance themselves, placing the focus entirely on the voices in the quotations. However, the journalist's own voice is present in implicit ways (Claquin 1993:67). The journalists' role is central because they manipulate the material to be quoted (Claquin 1993:45):

The quoting actor draws himself to the background, detaches his own responsibility, by referring to quotation. Quoted utterance becomes a formula that converts itself to a text. But the autonomy of the quotation is entirely fictive. (Claquin 1993:45; translation from French).

This genre is ambivalent, as journalists do decontextualise news items and opinions from other sources and recontextualise them in a press review, distancing themselves in the process (Claquin 1993). However, whenever material is recontextualised from another context, it creates new stories and establishes intertextual and -discursive links with other texts and discourses (Fairclough 1995; Johansson 2002). This can have several effects. Claquin (1993:60-63) claims that the goals of a radio press review are to establish mutual understanding, create polemical effects and surprise listeners. In addition, journalists create relationships not only with their listeners but also with those whom they quote. 


\section{Quotations and stances}

How are quotations used to bring basic facts, eyewitness evidence, expert knowledge or decisions and opinions into the news discourse (Charaudeau 1997:184-185)? A quotation basically mediates something from the immediate context (i.e., you said a moment ago), from a displaced context (i.e., last week you said in your interview) or from a hypothetical or fictional context (i.e., if they say) (Johansson 2002). These functions inform the moment of original utterance. Waugh (1995) observes that in informative news texts, quotations are constructed from a variety of sources such as interviews and documents. Quotations anchor the truthfulness and reliability of the news information, on one hand, and indicate the media interest on the other (Waugh 1995). Fairclough (1995) claims that a hierarchy exists in media texts between those who are quoted and those whose voices are marginalised.

Quotations are considered here from two perspectives. First, at the textual level, they are intertextual forms whose function is dependent on the genre and type of discourse (Fairclough 1992:110-112). Second, at the utterance level, they contain a stance. In every interaction, speakers or writers express a stance toward the content of their utterances. As Jaffe (2009:3) states, "there is no such thing as a completely neutral position" toward one's verbal expression. According to DuBois (2007: $163)$, stancetaking includes evaluating objects, i.e. events and things in the world.

\section{Data and method}

The data are from lemonde.fr, the digital newspaper of a major French newspaper. According to its video section, the newspaper has published videos regularly since 2006. On its site, the newspaper lists more than 400 videos that are organised in different sections. One particular section is devoted to Télézapping. As explained in the Introduction, Télézapping is a video press review that presents video excerpts from other French media. It can contain different types of material from sports news to everyday topics. For this analysis, two videos of political content were chosen. They are called "Sarkozy attaque, ses adversaires répliquent", (published October 28, 2011) and "Martine Aubry ne sera pas ministre" (published May 16, 2012). The first one was published in a situation in the autumn of 2011, when the French presidential elections started to surface as a media topic. 
The elections were held in the spring of 2012. The second video was published right after the new president, François Hollande, had taken office and started to form his government in May 2012. Martine Aubry was, at that time, the First Secretary of the Socialist Party, from the same party as the newly elected president. She was also his opponent in the party's primary elections in the fall of 2011, an election that she lost. In the analysis, these videos will be referred to as the "Sarkozy video" and the "Aubry video". The videos are in French, but in the examples, translated transcripts will be used (translation by the author).

In the analysis, first the basic characteristics will be examined. Then their stances and the "story narrative" will be analysed, and finally, the journalistic stance and hybridisation of this genre discussed. In the analysis, underlining will be used in cases where the speakers refer to a former speaking situation, and italics in order to highlight a focus on a certain evaluative words, such as nouns, adjectives or other linguistic elements.

\section{Press review videos and their basic characteristics}

\section{Video excerpts and media sources}

The press review of Télézapping is a genre that combines video excerpts from other media sources. In this sense, Télézapping resembles an ordinary press review, except it recontextualises material from broadcast and webcast sources, not from the print media.

The following example (Image 2) illustrates this. The origins of the video excerpts can be detected easily because the Télézapping video lists them on the opening screen.

The displayed list mentions six different broadcast media organisations. However, the excerpts are not found in the same order in the actual video. Some excerpts are used twice so that altogether there are fourteen video excerpts - or sound bites - in this press review, included in the following order: iTélé, BFM-TV, France2, iTélé, LCI, LCI, BFM-TV, iTélé, iTélé, iTélé, BFM-TV, France 3, TF1, and France3. The logo of every TV network displays on the screen when the video excerpt is used. The same applies in the Aubry video.

The video excerpts are short and are separated by cuts that create a rapid rhythm. Both videos contain approximately 400 words and last less than two minutes. 


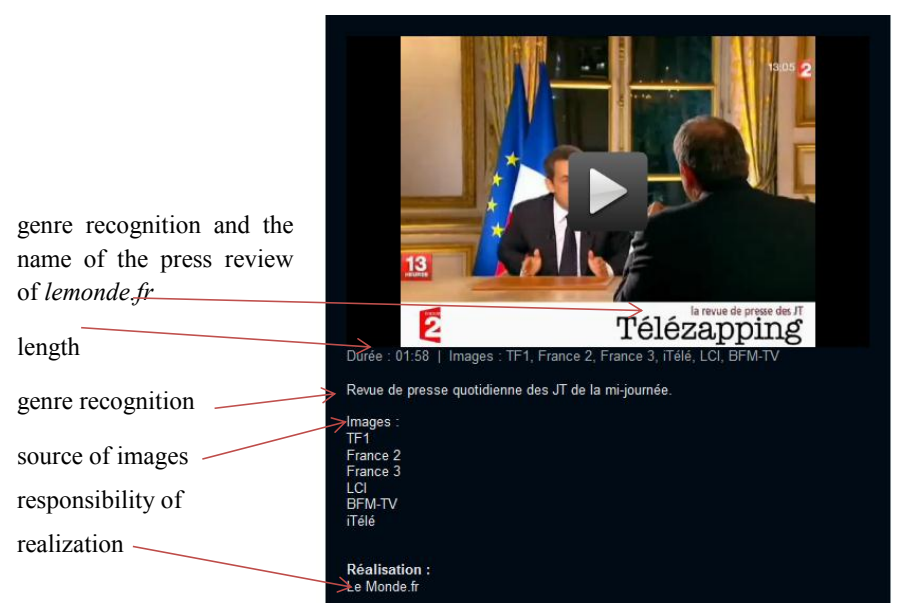

Image 2. Initial screen from the Télézapping press review, displaying the list of its sources (Le Monde, 28.10.2011).

\section{Video quotations}

As video excerpts are recontextualised from other media instances, they establish intertextual links within themselves. Therefore, they can be considered video quotations because their main function is to present an opinion or a view expressed by someone in a previous media situation. Whose opinion is recontextualised? In the Sarkozy video, the quotations are from the president himself, and, as articulated in the video's headline, his adversaries, including four French politicians and two journalists. In the Aubry video, the roles are reversed: mostly journalists talk and only two politicians are included.

What kind of speech situations do these excerpts exemplify? In these two cases, excerpts are usually taken from interviews. In the Sarkozy video, most of the situations involve different types of interviews, with one or two journalists. In some cases, journalists cannot be seen, but their presence can be assumed from the scene. One of the sources is a television news broadcast with two news anchors. In these cases, journalists are quoted, but their identities are not revealed; they are represented only by their professional roles.

Two of the excerpts also contain written quotations that appear on the screen. In the Sarkozy video, one quotation appears as a screenshot from a webpage. In the Aubry video, text displayed across the screen reads "Urgent. Entourage of Martine Aubry informs that she will not 
be in the government (iTélé)."The video excerpts and their scenes are summarised in the following tables:

\begin{tabular}{|l|l|l|}
\hline $\begin{array}{l}\text { Order of the } \\
\text { video quote }\end{array}$ & Quoted speaker & $\begin{array}{l}\text { Original communication } \\
\text { situation }\end{array}$ \\
\hline 1. & Nicolas Sarkozy & interview \\
\hline 2. & Marine Le Pen & interview \\
\hline 3. & Nicolas Sarkozy & interview (1 interviewer) \\
\hline 4. & Bénoit Hamon & interview \\
\hline 5. & Pierre Moscovici & radio interview \\
\hline 6. & Nicolas Sarkozy & interview \\
\hline 7. & Journalists & TV news/web-page \\
\hline 8. & Nicolas Sarkozy & interview (2 journalists) \\
\hline 9. & Bénoit Hamon & interview \\
\hline 10 & Nicolas Sarkozy & radio interview \\
\hline 11. & Pierre Moscovici & interview \\
\hline 12. & Marine Le Pen & interview \\
\hline 13. & Eva Joly & interview \\
\hline 14. & Journalist & interview \\
\hline
\end{tabular}

Table 1. Persons quoted and their original communication situation in the Sarkozy video.

\begin{tabular}{|l|l|l|}
\hline $\begin{array}{l}\text { Order of the } \\
\text { video quote }\end{array}$ & Quoted speaker & $\begin{array}{l}\text { Original communication } \\
\text { situation }\end{array}$ \\
\hline 1. & Journalist & TV news \\
\hline 2. & Journalist & report \\
\hline 3. & $\begin{array}{l}\text { Unidentified person } \\
\text { with a journalist }\end{array}$ & interview in TV news \\
\hline 4. & Marine Le Pen & interview \\
\hline 5. & $\begin{array}{l}\text { Unidentified person } \\
\text { with a journalist }\end{array}$ & interview \\
\hline 6. & Jean-François Copé & interview? press conference? \\
\hline 7. & Journalist & report \\
\hline 8. & Journalist & $\begin{array}{l}\text { interview? journalist as } \\
\text { commentator }\end{array}$ \\
\hline
\end{tabular}

Table 2. Persons quoted and their original communication situation in the Aubry video. 
In cases where there is a question mark, the origin of the quotation is not indicated in the video.

Finally, these press review videos do not contain any journalistic voice of the video editor. The previously displayed media excerpt is left unexplained, as are the original communicative situations and speaker identities. In this sense, the traditional principles of the journalistic practise of quoting fidelity become somewhat fuzzy. However, there is an implicit journalistic voice in the videos, which will be analysed below. In the next two sections, the sequential order of quoted material and the stances expressed in these quotations are analysed.

\section{Hybridisation of genre}

\section{Conflicting stances forming a struggle of opinions}

What are these video quotations? They do not represent memorable moments that another media organisation has been able to capture on "film". Instead, they are intertexts, linked because they share the same topic of the day. All opinions expressed in the Sarkozy video belong to the political discourse of the French and European public spheres, and the stances concern political events and recent political propositions. A translated transcription of the Télézapping video's content follows below:

Headline: Nicolas Sarkozy attacks, his adversaries contradict 1 Nicolas Sarkozy: $\quad$ If we did not have an agreement yesterday evening, not only Europe would have been heading for a catastrophe, but the whole world.

2 Marine Le Pen: $\quad$ He dramatised in order to appear to be the saviour of Europe, even of the whole world, I think he said.

3 Nicolas Sarkozy: The 35- hour workweek has been a crazy thing. Who has paid for it? Less educated workers and employees. And it has proven to be a social catastrophe and an economic catastrophe.

4 Benoit Hamon: $\quad$ To explain that it was the socialists before or the socialists yet to come who are responsible for this, that we have an 
5 Pierre Moscovici:

6 Nicolas Sarkozy:

7 Journalists:

8 Nicolas Sarkozy:

9 Benoit Hamon:

10 Nicolas Sarkozy:

11 Pierre Moscovici:

12 Marine Le Pen:

13 Eva Joly: unemployment rate this high and that people are also vulnerable, it is rather ridiculous.

[...] from the president, he tried to present his future campaign on what grounds? First, it is the other's fault; it's the fault of socialists.

When I hear that we have to employ 60,000 extra teachers. But where do we find the money?

François Hollande's answer today in Le Monde. [On the screen a quote from Le Monde's webpage] "Hollande answers to Sarkozy: he won't get away with his results".

Nicolas Sarkozy, he said [i.e., François Hollande], does not get away with his results and [François Hollande] criticises him to have made the French more vulnerable, more dependent on public $d e b t$, and he qualifies also the future measures of the cure of austerity as improvised, running away beforehand.

We have decided to readjust our previsions and drop it one percent.

The result, by the way, is that we have to lower our growth previsions so next year, there will be more unemployment, more job cuts.

The problem is not the credit rating agencies. The problem is that we spend too much.

There is only one perspective for Europe, that is austerity, no perspective of growth. He spoke more about general feelings, there is nothing else than a cure of austerity.

I found that he did not propose anything. It was a triple zero: he had nothing for the 
14 Journalist:

French, nothing for Europe, and nothing for the environment.

Nicolas Sarkozy is not in a campaign, he is not a candidate, but yes, he actually started to campaign.

This video contains five quotations from Nicolas Sarkozy (quotations 1, 3, 6, 8, and 10). The other quotations (2, 4, 5, 7-9, and 11-14) come from politicians who comment on Sarkozy's opinions. The latter quotations are organised, or edited, in a particular sequential order. The press review gathers circular media material and remixes it together such that the quotations' dialogicality is "mise en scène" (put on the stage). The opposing comments are organised such that they are responses and comments on Sarkozy's opinions. In these quotations, the politicians use expressions that refer to the media situation in which Sarkozy has spoken. They contain speech verbs, such as he said, to explain, and he tried to present (underlined in the text above). In his stances, Sarkozy aligns himself with decision-making at the European level (quotation 1) and disaligns himself from his political opponents (quotations 3, 6, 8, and 10). All stances in the opposing comments challenge Sarkozy's opinions and construct disalignment from him.

What type of discursive sequentiality is constructed? The first two quotations ( 1 and 2) form an interactional pair. In quotation 1, Sarkozy refers to an agreement concerning the financial help that European countries are providing to Greece. Sarkozy's opinion consists of a stance that contains a hypothetical form, if. He describes a possible situation without political agreement with an affective noun, a catastrophe. Thus, he underlines the importance of the agreement. In the quotation 2, a comment from his political opponent, the verb announces an upcoming negative evaluation, dramatised. This politician interprets Sarkozy's opinion as displaying his identity. In this comment, Sarkozy's political identity is interpreted as an exaggeration, saviour.

The following three quotations $(3,4$, and 5$)$ form the next subsequence. In quotation 3, Sarkozy refers to the French system of a 35hour workweek, established by the socialists in the 1990s. Sarkozy's opposing stance is anchored by the choice of an affective adjective, crazy, and the rhetorical question, Who has paid for it? He then answers himself, repeating the noun, catastrophe.

Sarkozy's evaluation is challenged by two politicians. In quotation 4, the politician questions the grounds for Sarkozy's claim. The 
politician's stance contains a negative and affective evaluation that targets Sarkozy's entire opinion, it is rather ridiculous. Next, in quotation 5 , there is an interpretation of Sarkozy's opinion as a communicative act of blame, First, it is the other's fault; it's the fault of socialists.

For the next pair, in quotation 6, Sarkozy comments on a political proposition made by François Hollande. Here, Sarkozy's stance is anchored once again in a rhetorical question with which he opposes a political proposition, But where do we find the money? Quotation 7 , consists of a clip from television news in which two journalists explain François Hollande's response. First, the journalists explain a quotation from Le Monde that appears on the screen. The quotation contains François Hollande's claim about Sarkozy's results and their insufficiency for the current political situation, he won't get away with his results. With this remark, Hollande challenges Sarkozy as a political actor. The challenge is repeated by the journalists. Hollande's critique consists of enumerating points referred to as the results of Sarkozy's five years as head of state.

The next sub-section of the transcript, from quotation 8 to 11 , contains opinions that are interrelated. In quotations 8 and 9, Sarkozy makes claims about the economic situation including how to respond to it and the reasons behind it. In opposing comments, quotations 10 and 11, the consequences of Sarkozy's opinions are elaborated, demonstrating the dismal resulting future.

Video quotations 12 and 13 are more general and do not target any specific point in Sarkozy's opinions. They are aligned with two previous comments because they refer to a future without hope, a cure of austerity. Their stances are negative, nothing else, he did not propose anything, a triple zero. In quotation 13, the stance is elaborated through the repetition of the phrase nothing for.

The last video quotation, quotation 14, displays a journalist formulating a question in an interview. He first states of Sarkozy, he is not a candidate, but he then reverses this with discursive connectives, but yes. The journalist's stance is an evidential one because he presents Nicolas Sarkozy as a presidential candidate, he actually started to campaign. This quotation constitutes a coda for this press review 'narrative' because this quotation is positioned to appear as if the journalist expressing listened to all the previous conflicting quotations presented. It can also be considered a news announcement. In sum, the discursive order of the video could be characterised as a struggle of 
opinions in the search for legitimation of one's own stance, ending with a coda by a journalist.

\section{Stances constructing a news announcement and its background}

In the video about Martine Aubry, the voices quoted are mostly journalists with different stances.

Headline: Martine Aubry is not going to be minister

1 Journalist:

2 Journalist:

3 Unidentified person and a journalist:

4 Marine Le Pen:

5a Unidentified person:
In the afternoon, we will find out the composition of the government of Mister Ayrault. About fifteen ministers, a couple of women as François Hollande promised, but apparently Martine Aubry won't be in it.

The formation has been confirmed this morning. Martine Aubry is not part of the government of Jean-Marc Ayrault. To summarise sufficiently her position, it was "Matignon or nothing" [i.e., Prime Minister's office and residence].

When François Hollande called her Monday afternoon to say "it's not going to be you, it's going to be Jean-Marc Ayrault", she draws the conclusion that she does not want to enter the government if it is not to run it. Besides, this was not necessarily François Hollande's affair. He wanted to give an overall image of all coming together.

I think that this woman has nothing to offer to France so, as far as I am concerned, I am happy about her absence from the government. But once again, $I$ remark that this is more a showdown than a community coming together.

There is a conflict between them that seems to be important. We can remember what they said during the primary election. It 
5 b Journalist:

5c Unidentified person: 6 Jean-François Copé:

7 Journalist:

8 Journalist: is after all very unusual at that level, even publicly.

Yes, it was very bitter at that moment, but isn't it going to finally [incomprehensible] [continues, incomprehensible]

Everyone knows how much Martine Aubry and François Hollande despise each other. Besides, the primary elections were its theatre.

She chose to stay as the head of the Socialist Party and lead the campaign to the parliamentary elections. She will do $i t$, she confirmed it a moment ago. She will do it in solidarity and loyalty with the new leader of the majority, whose name is Jean-Marc Ayrault.

I think she told the truth when she said that she was not surprised, that she found it normal. She is most certainly going to campaign, after she leaves the head of the party. She has announced it. She does not intend to stay there.

These video quotations are organised differently than those in the Sarkozy video. The first quotation is a news announcement. It depicts a news anchor reading the news. However, it does not contain confirmed information because the stance is constructed with a linguistic element underlining the uncertainty, apparently. Quotation quickly changes this situation by confirming the information in the first claim The formation has been confirmed this morning. Then, in quotation 2, the journalist provides a new piece of information - the reason for Martine Aubry's absence from the government - "Matignon or nothing". Here, the stance mediates this information.

These two quotations provide a starting point for the rest of the video's discursive order. The following quotations align with these first ones, adding new sides to this information, with different types of stances. In quotation 3, the speaker uses a quotation that describes a telephone call. This mediates the information that the leader of the government allegedly informed his choice to Aubry days before. At the 
same time, it clarifies the intention of François Hollande by using a verb, wanted. This is underlined by the uncertainty marker, not necessarily.

In contrast, in quotation 4 , a politician constructs her subjective stance by using a first-person personal pronoun with reference to an emotional state of mind - I think, as far as I am concerned, I am happy — and offers a negative evaluation of her political opponent. At the end of her quotation, she qualifies the formation of government with an affective noun, showdown. This point is further explained in subsequent quotations. In quotations $5 \mathrm{a}, 5 \mathrm{~b}$ and $5 \mathrm{c}$, the speakers qualify a political conflict between President Hollande and Martine Aubry. They cautiously evaluate its nature - seems to be important, but express explicit opinions in the quotation 6 .

The next two video excerpts form a pair. In quotation 7 , a journalist provides further explanation, which is based on professional reasons rather than on the conflict. The journalist explains this situation as Aubry's choice - she chose - and the nature of her political commitment, she will do it in solidarity and loyalty. This view is anchored with a speech verb, she confirmed it a moment ago. In quotation 8, a journalist who is not identified on the screen, discusses the female politician's plan to resign as head of the party. This stance also offers a type of coda - it wraps up the "news story". In this press review, the search for legitimation is based on the evidence offered for the initial news announcement, be it of a "behind the scenes" nature (i.e., a political conflict) or the choices and future plans of the politician.

\section{Implicit journalistic stance and the hybridisation of genre}

In Télézapping, no journalist's voice explicitly explains or comments on the video quotations or the editing. However, the press review is based on journalistic work. Before editing, a selection and an interpretation of the material must occur. The power and control of this genre remain in the hands of video journalists. The journalist's stance unfolds in the way the press review is assembled.

As we have observed, the video press review is based on "remixing" opinions. It remediates material from other media sources that the journalist has selected and organised into a new order. The composition of these pieces is based on video editing. Quotations follow each other at a fairly rapid pace, and the rhythm that evolves in the videos is repetitive and punctuated by cuts. This new discursive order dramatises 
the story, which builds from the quotations. In this new context, they form a new text.

The journalist's indirect stance consists of the construction of a novel news story. In this way, the journalist contributes to the hybridisation of the press review genre. The genre has a complex nature. It constitutes a press review in the sense that it remains true to journalistic selection and interpretation of media sources. However, the novel aspect is a montage of several video excerpts that turns them into a new story. Although it is an institutional, popular genre, the video press review resembles user-generated political mash-up videos, which also uses the practise of bricolage to compose a new text (Edwards and Tryon 2009; cf. Deuze 2006). In the new text, two or more videos or other types of sources are added into a new work that "generates new meanings through juxtaposition of the original source materials" (Edwards \& Tryon 2009). The new work situates itself in the practises of the culture of recombination and reproduction (Edwards \& Tryon 2009). In traditional press reviews, the journalist's role is to show and to comment; in video press reviews, this role is far more complex and consists not only of showing and informing but also in commenting indirectly.

\section{Conclusion}

In this paper, video press reviews based on video quotations have been analysed. Two different cases of press reviews have been presented. Quotations consisted of political opinions whose stances developed into a new story.

In video press reviews, as in traditional press reviews, the journalistic stance is based on the selection and interpretation of media sources. The video press review differs from a traditional written one because it contains video editing that remixes opinions, but does not contain any comment by the editing journalists. Therefore, the video press review becomes a hybrid genre that demonstrates the struggles of legitimation of stances or evidence to support a news announcement. It reveals features of playfulness that resemble mash-up videos familiar in online video culture ( $C f$. Edwards \& Tryon 2009). It constructs its own story, interpreting and commenting on the media situation. Concurrently, it also participates in the discussion of the political event in the media. In this respect, it can still be considered an opinion-related genre. The 
circularity and remediation of media material in this way to viewers, readers and users can be considered a feature of 'neojournalism'.

The press review is a communicative genre. Any media or digital genre is a social encounter between social actors within at least two frames of interaction (Lauerbach \& Fetzer 2007). The first frame is that of the journalists constructing a press review of intertexts that are related into a new video story. The second frame of interaction of the media or digital discourse is that between the media instance and the audience(s). The hybrid nature of this genre has an effect on its viewers. In the present media and digital cultures, viewer participation can be ambivalent and ambiguous. The liquidity is not only about the characteristics of late modern journalism but is a fluctuation between the practises of modern journalism and the practises media audience have experienced in the recent past. Therefore, there can be three simultaneous frames of interpretation for the viewers.

If a video press review is interpreted within the traditional, "oldfashioned" frame of news as disseminating information to citizens who have the right to know it so they can participate in the practises of democratic society, then viewers are confused or even disappointed. Confronted with video press reviews, viewers can experience great agitation because they do not find appropriate journalistic information about who is quoted and when the video quotation was published previously. This can lead viewers to judgements about the "deterioration" of news information.

The second frame of interpretation could be that of news as entertainment. Almost two decades ago, Fairclough (1995) claimed that the major tensions in media discourse were those between information and entertainment and the intertwinement of public- and private-sphere material. This resulted in "infotainment." Besides funny videos published in digital newspapers, video press reviews could most certainly be considered infotainment. Viewers with this mind-set would evaluate their content as amusing but might not be concerned with the political content.

The third possibility is to consider the reception frame as a liquid frame. Viewers are users who gather their own news material and are able to recognise the characteristics of this remix as familiar to digital culture. They are requested to participate in the decomposition of this information. It is assumed that they know the sources of the video quotations and that they know the règles de jeu. In other words, they 
know how to read media quotations and find the "serious" information behind the playful composition.

\section{Videos}

Sarkozy attaque, ses adversaires répliquent. Télézapping lemonde.fr. Published 28.10.2011 Retrieved from http://www.lemonde.fr/tele-zapping/video/2011/10/28/ sarkozy-attaque-ses-adversaires-repliquent_1595819_811987.html

Martine Aubry ne sera pas ministre. Télézapping lemonde.fr. Published 16.5.2012. Retrieved from http://www.lemonde.fr/politique/video/2012/05/16/telezappingmartine-aubry-privee-de-ministere_1702433_823448.html

\section{References}

Bauman, Z. (2005). Liquid Life. Oxford, Cambridge, Malden: Polity Press.

Bauman, Z. (2011). Culture in a Liquid Modern World. Oxford, Cambridge, Malden: Polity Press.

Bock, M.A. (2011). Newspaper journalism and video: Motion, sound, and new narratives. New Media Society 14, 600-616.

Charaudeau, P. (1997). Le discours d'information médiatique. La construction du miroir social. Nathan: Paris.

Claquin, F. (1993). La revue de presse: Un art de montage. Langage et Société 64, 4371.

Deuze, M. (2006).Participation, Remediation, Bricolage: Considering Principal Components of a Digital Culture. The Information Society, 22, 63-75.

Deuze, M. (2008). The Changing Context of News Work: Liquid Journalism and Monitorial Citizenship. International Journal of Communication, 2, 848-865.

DuBois, J. (2007). The Stance Triangle. In R.Englebretson (Ed.), Stancetaking in Discourse (pp.139-182). Amsterdam: John Benjamins.

Edwards, R. L., \& Tryon, Ch. (2009). Political Video Mashups as Allegories of Citizen Empowerment. First Monday, 14(10) 5, October 2009. Retireved from http://www. firstmonday.org/htbin/cgiwrap/bin/ojs/index.php/fm/article/view/2617/2305

Erbe, J. (2007). "What Do the Papers Say?" How Press Reviews Link National Media Arenas in Europe. The Public, 12(2), 75-92.

Fairclough, N. (1992). Discourse and Social Change. London: Polity Press.

Fairclough, N. (1995). Media Discourse. London: Edward Arnold.

Gere, Ch. (2002). Digital Culture. Reaktion Books: London.

Jaffe, Alexandra (2009). Introduction. The Sociolinguistics of Stance. In A. Jaffe, (Ed.), Stance. Sociolinguistic perspectives (pp. 3-28). Oxford: Oxford University Press. 
Johansson, M. (2002). Sequential Positioning of Represented Discourse in Institutional Media Interaction. In: A. Fetzer \& C. Meieirkord (Eds.), Rethinking Sequentiality. Linguistics Meets Conversational Interaction (pp. 249-271). Amsterdam: Benjamins. Johansson, M. (2012). Political Videos in Digital News Discourse. In L. Berlin, \& A. Fetzer, (Eds.), Dialogue in Politics (pp. 43-68). Amsterdam: John Benjamins.

Lauerbach, E. G., \& Fetzer, A. (2007). "Introduction.” In A. Fetzer, \& E. G. Lauerbach, (Eds.), Political Discourse in the Media (pp. 3-28). Amsterdam: John Benjamins.

Layton, C. (2008). The Video Explosion. American Journalism Review, January 2008. Retrieved from http://www.ajr.org/Article.asp?id=4428

Rossi, A. (2011). Page One: Inside the New York Times. Documentary. http://www. imdb.com/title/tt1787777/

Wallace, S. (2009). Watchdog or witness? The Emerging Forms and Practices of Videojournalism. Journalism, 10, 684-701.

Waugh, L. R. (1995). Reported Speech in Journalistic Discourse: The Relation of Function and Text. Text, 15(1), 129-173. 